D.O.I.: $10.3895 / \mathrm{S} 1808-04482011000400011$

\title{
AVALIAÇÃO DOS PROCESSOS DE APRENDIZAGEM E COOPERAÇÃO PARA INOVAÇÃO: UM ESTUDO COMPARATIVO ENTRE INDÚSTRIAS DE CACHAÇA DO BREJO PARAIBANO
}

\section{EVALUANTION OF LEARNING PROCESS AND COOPERATION FOR INNOVATION: A COMPARATIVE STUDY BETWEEN RUM INDUSTRIES OF BREJO PARAIBANO}

\author{
Nívea Marcela Marques Nascimento de Macêdo ${ }^{1}$; Raquel Andrade Barros ${ }^{2}$; Gesinaldo Ataíde \\ Cândido ${ }^{3}$ \\ ${ }^{1}$ Centro Universitário de João Pessoa - UNIPÊ - João Pessoa - Brasil \\ niveamarcela@ig.com.br \\ ${ }^{2}$ Universidade Federal de Campina Grande - UFCG - Sousa - Brasil \\ barrosrab@gmail.com \\ ${ }^{3}$ Universidade Federal de Campina Grande - UFCG - Campina Grande - Brasil \\ gesinaldo@pq.cnpq.br
}

\begin{abstract}
Resumo
A capacidade de construir novas competências através de mecanismos de aprendizado e cooperação torna-se fundamental para a obtenção de vantagens competitivas. Empresas que constroem um ambiente favorável à troca de conhecimentos, informações e experiências estão mais propícias a desenvolver mecanismos para diferenciação em seus produtos e processos, obtendo com isso maior inovação. Dessa forma, o presente trabalho tem como objetivo realizar um estudo comparativo dos processos de aprendizagem e cooperação em duas indústrias de cachaça do Brejo Paraibano sob a ótica de indicadores propostos por Stallivieri e Souza (2008). A pesquisa caracteriza-se como de natureza exploratória e descritiva, uma vez que envolveu a exposição e análise das características de inovação e estrutura de aprendizagem e cooperação de duas empresas agroindustriais. Os resultados apontam que as empresas apresentam dificuldades externas relacionadas à falta de uma cultura social de cooperação e aprendizado na localidade, o que não favorece a inovação das empresas. No entanto, é possível observar que uma das industrias introduziu algumas inovações, contando principalmente com características intrínsecas do administrador no seu intento de buscar novas tipologias de produto.
\end{abstract}

Palavras-chave: aprendizagem; inovação; indústria de cachaça.

\section{Introdução}

Nos últimos anos, consolidou-se a ocorrência de uma modificação na economia mundial, nas formas de produção e conceitos relacionados, cujo contexto passa a estar diretamente relacionado à produção e uso do conhecimento. Isto porque as empresas passaram a atuar sob a 
prerrogativa da necessidade da introdução e difusão de tecnologias da informação e comunicação, que aprimoram os processos produtivos, inovam produtos e diferenciam empresas.

Estes fatores são decorrentes da importância verificada na adoção de iniciativas de aprendizagem nas organizações, de estímulo à cooperação e trabalho conjunto orientado. Empresas que constroem um ambiente favorável à troca de conhecimentos, informações e experiências estão mais propícias a desenvolver mecanismos para diferenciação em produtos e processos. No contexto atual, a pesquisa e a cooperação entre empresas e setores são vistas como elemento distintivo entre as organizações de sucesso. A vulnerabilidade para com aspectos que desestruturam uma organização diminui em contrapartida a um aumento do fluxo de interação e comunicação no caso de empresas que implantam sistemas de cooperação para inovação.

Alguns autores desenvolveram modelos de avaliação ou análise da capacidade tecnológica das empresas. Destaca-se o trabalho de Dahlman et al. (1987) e Lall $(1992,1994)$ que visualizaram essas capacidades tecnológicas categorizadas por funções. Segundo os autores, o modelo sugere que a acumulação se processa das categorias mais simples para as mais complexas. Em algum momento, a empresa se tornará tecnologicamente madura, capaz de dispor com antecedência os requisitos necessários para a eficiente atuação no mercado.

Neste contexto, a capacidade de construir novas competências através de mecanismos de aprendizado interativo torna-se fundamental para a obtenção de vantagens competitivas (Campos et al. 2003). É válida a observação de como as empresas se colocam nesse sentido, como priorizam meios que propiciem o aprendizado contínuo, e como se dão seus resultados. Ou seja, se é possível atingir uma capacidade inovativa oportuna e adequada dada as características de mercado e do produto ou serviço em questão.

Assim, a presente pesquisa tem como objetivo realizar um estudo comparativo dos processos de aprendizagem e cooperação em duas indústrias de cachaça do Brejo Paraibano sob a ótica de indicadores propostos por Stallivieri e Souza (2008). Para a consecução deste objetivo, foi realizado uma estudo exploratório e descritivo, conduzido sob a forma de um estudo de caso múltiplo em duas empresas produtoras de cachaça na região do Brejo no Estado da Paraíba. Como técnica de pesquisa principal foi utilizada a análise de conteúdo, consubstanciada da análise de dados secundários e a observação não participante.

Além deste conteúdo introdutório, o artigo apresenta um referencial teórico que aborda a questão do conhecimento e da inovação, verificando pontos como sua importância e conceituação. Posteriormente abordaram-se os procedimentos metodológicos que orientaram a pesquisa. Por fim, tem-se os resultados encontrados com a análise das empresas em questão e as considerações finais do estudo. 


\section{Aporte teórico}

\subsection{Aprendizagem e cooperação}

É amplamente aceito que a difusão de novas tecnologias são essenciais para que haja um incremento na produtividade e no desempenho das empresas. A inovação, porém, não se constitui um evento isolado, mas resulta de um processo no qual estão envolvidas várias fontes de conhecimento.

Dessa forma, o direcionamento de uma empresa na busca pelo desenvolvimento de inovações está atrelado a própria trajetória de conhecimento acumulado na firma (NELSON; WINTER, 2002). E dependendo da capacidade de absorção de conhecimento da firma, o estoque de conhecimento acumulado é que vai direcionar e delimitar a capacidade de absorção de novos conhecimentos.

Independente da inovação acontecer em termos de processo ou produto, é o estoque de conhecimento que determinará a velocidade das intenções inovativas. Para Albagli e Maciel (2004), a capacidade de processar e recriar conhecimento assume igual importância a produzir um conhecimento novo. Contudo, o elemento essencial no processo de inovação consiste na transformação do conhecimento em ação, desde que a empresa tenha boa capacidade para gerenciamento de ativos intangíveis na forma de conhecimento.

A criação e utilização do conhecimento é responsabilidade apenas de indivíduos, uma vez que não há possibilidade de expressá-lo sob forma palpável, apenas por demonstração dos que o detém. Dessa forma, a gerência de ativos tangíveis se difere da gerência de ativos intangíveis, uma vez que este último requer um grau de habilidade maior para lidar com processos diferenciados (EDVINSSON; MALONE, 1998).

Constata-se a partir das observações já realizadas que a posse do conhecimento é o principal fator para elevar a competitividade das empresas. No entanto, a utilização do conhecimento como arma competitiva só será possível se as firmas estiverem orientadas para geração e absorção de novos conhecimentos.

Conforme Lundvall (1992), o processo através do qual torna-se possível a criação e incorporação de novos conhecimentos é caracterizado como aprendizado. E além disso, o aprendizado contribui para melhorar procedimentos de busca e aperfeiçoar habilidades de desenvolver e comercializar bens e serviços. McGee e Prusak (1994) definem o aprendizado como sendo a aquisição de novas capacidades e perspectivas e não a aquisição de fatos novos. E assim torna-se dever da organização criar condições que favoreçam o aprendizado e aproveite o potencial de aprendizagem dos indivíduos.

Em Bessant et al. (1999), o aprendizado é caracterizado da seguinte forma: 
Que o mesmo não é automático; é necessário investimento explícito para aprender. O aprendizado pode envolver o domínio e a mudança desde tarefas corriqueiras como processos mais intensivos em conhecimento e transformações radicais; sendo que quanto mais radical a mudança, maior a necessidade do investimento em aprendizado. Aprender a aprender é fundamental e envolve tanto componentes formais como aqueles tácitos (e portanto seu caráter interativo e dependente do contexto) (BESSANT, 1999, p.50).

Existem quatro características do aprendizado que segundo Malerba (1992) devem ser consideradas na análise do fenômeno:

- Processo orientado: acontece no interior da firma e se utiliza da mobilização de diversas instancias organizacionais e da elaboração de uma estratégia particular que define as principais direções dos esforços de capacitação dos agentes;

- O aprendizado tecnológico advém de diversas fontes de conhecimento, internas ou externas à firma;

- Em terceiro lugar, o aprendizado é visto como processo intertemporal e cumulativo, que amplia continuamente o estoque de conhecimentos da firma, diferenciando-a de outros agentes;

- Por fim, este aprendizado induz não apenas a incorporar as inovações incrementais, mas também identificar novas oportunidades produtivas e tecnológicas, possibilitando a expansão para novos mercados;

A forma como os indivíduos adquirem informações dos mais diversos agentes desenha as formas de aprendizado. E este pode ser considerado como sendo um processo contínuo e interativo, o qual induz a criação do conhecimento, das competencias e habilidades individuais.

Vale salientar que o aprendizado não é um processo simplificado, uma vez que as capacitações tecnológicas não são fáceis de serem repassadas e codificadas. Sendo assim, essa transmissão de conhecimentos pode ser facilitada através de práticas cooperativas (CASSIOLATO et al. 2005). E a intensificação dessas práticas de cooperação no compartilhamento de informação e conhecimento no decorrer do tempo age como fortalecedor da comunicação entre os indivíduos, consolida as ações e estratégias desenvolvidas.

A confiança entre os atores no processo de compartilhamento de informações envolve contextos culturais. Portanto, as instituições são imprescindíveis no gerenciamento das relações, sejam elas políticas ou culturais. Investimentos nestas interações são importantes, pois trazem crescimento e competitividade não apenas coletivo, mas também individual. A idéia de aglomeração está ligada diretamente à competitividade. Logo, a capacidade de interação entre os atores na geração de inovações e ambientes inovadores é um desafio, dada a dificuldade de cooperação (CASSIOLATO; LASTRES, 2002).

Para Casarotto Filho e Pires (1999), a construção de uma ambiência de cooperação e 
desenvolvimento necessita de um fator determinante, que é uma cultura social bastante aprimorada. Ainda que o território possua grandes potencialidades em termos de recursos naturais, o principal agente requerido para a construção de um ambiente cooperativo é o indivíduo. Isto porque por meio da população acontecem as diversas ligações com o território e com ambientes externos.

De acordo com pesquisas realizadas, o caráter cooperativo entre as empresas locais gera um maior número de inovações. Fato que não ocorre com empresas que trabalham individualmente (ALBAGLI; MACIEL, 2004). Apesar de tais abordagens favoráveis à cooperação, esse fenômeno ainda possui um baixo grau na indústria brasileira. Assim, estudos empíricos que enfocam as aglomerações como facilitadoras de articulações cooperativas e promotora de incrementos do potencial inovativo e aumento de produtividade têm demonstrado a eficiência de tal abordagem (STALLIVIERI; SOUZA, 2008).

Para os autores supracitados, esse procedimento avança no sentido de obter um tratamento analítico dos processos de aprendizado através da interação, objetivando avaliação de prováveis desdobramentos, as intensificações dessas práticas e suas influências sobre o desempenho inovativo. Sendo assim, a partir da utilização de alguns indicadores estabelecidos por Stallivieri e Souza (2008) este estudou buscou analisar os processos de aprendizado e cooperação como contribuição empírica para os aportes teóricos existentes sobre o tema em questão.

Quadro 1 - Indicadores de Aprendizado e Cooperação

\begin{tabular}{|c|c|}
\hline Indicadores & Eventos Captados \\
\hline \multicolumn{2}{|r|}{ 1) Indicadores de Esforço Inovativo } \\
\hline Constância na Realização de P\&D & Realização de P\&D na empresa e; Aquisição externa de P\&D; \\
\hline $\begin{array}{l}\text { Constância na Aquisição de Novas } \\
\text { Tecnologias }\end{array}$ & $\begin{array}{l}\text { Aquisição de máquinas e equipamentos que implicaram em significativas } \\
\text { melhorias tecnológicas e; Aquisição de outras tecnologias (softwares, } \\
\text { licenças, patentes, marcas e segredos industriais). }\end{array}$ \\
\hline $\begin{array}{l}\text { Constância no Esforço Pré- } \\
\text { Inovativo }\end{array}$ & $\begin{array}{l}\text { Projeto industrial associado a produtos/ Processos tecnologicamente novos ou } \\
\text { significativamente melhores e; Programa de treinamento associado à } \\
\text { introdução de produtos/ processos tecnologicamente novos ou } \\
\text { significativamente melhores }\end{array}$ \\
\hline $\begin{array}{l}\text { Constância na Atualização } \\
\text { Organizacional }\end{array}$ & $\begin{array}{l}\text { Implementação de Programas de gestão da qualidade ou de modernização } \\
\text { organizacional e; Novas formas de comercialização ou de distribuição de } \\
\text { produtos novos ou significativamente melhorados }\end{array}$ \\
\hline Esforço de Treinamento & $\begin{array}{l}\text { Treinamento na empresa; Treinamento em cursos técnicos realizados no } \\
\text { arranjo; Treinamento em cursos técnicos realizados fora do arranjo; Estágios } \\
\text { em empresas fornecedoras ou clientes e; Estágios em empresas do grupo }\end{array}$ \\
\hline $\begin{array}{l}\text { Esforço de Absorção de Recursos } \\
\text { Humanos (RH) }\end{array}$ & $\begin{array}{l}\text { Contratação de técnicos/Engenheiros de outras empresas do arranjo/ } \\
\text { Contratação de técnicos/ Engenheiros de empresas fora do arranjo; Absorção } \\
\text { de formandos dos cursos universitários localizados no arranjo ou próximos e } \\
\text { Absorção de formandos dos cursos técnicos localizados no arranjo ou } \\
\text { próximo }\end{array}$ \\
\hline $\begin{array}{l}\text { Aprendizagem Interna } \\
\text { Departamento de P\&D }\end{array}$ & Departamento de P\&D como fonte de informação relevante para inovação \\
\hline $\begin{array}{l}\text { Aprendizagem Interna Demais } \\
\text { Fontes }\end{array}$ & $\begin{array}{l}\text { Área de produção; Área de vendas e marketing; Serviços de atendimento aos } \\
\text { clientes }\end{array}$ \\
\hline \multicolumn{2}{|c|}{ 2) Indicadores de Aprendizagem Externa e Ações Cooperativas } \\
\hline Aprendizagem Vertical & Fornecedores de Insumos (equipamentos, matérias-primas) e; Clientes \\
\hline Aprendizagem Horizontal & Concorrentes e; Outras empresas do setor \\
\hline Aprendizagem com Instituições de & Universidades e Institutos de Pesquisa \\
\hline
\end{tabular}




\begin{tabular}{|c|c|}
\hline Ciência e Tecnologia & \\
\hline $\begin{array}{l}\text { Aprendizagem com Serviços } \\
\text { Especializados }\end{array}$ & $\begin{array}{l}\text { Centros de Capacitação Profissional, de assistência técnica e de manutenção; } \\
\text { Instituições de testes, ensaios e certificações e; Empresas de consultoria }\end{array}$ \\
\hline $\begin{array}{l}\text { Aprendizagem com Demais } \\
\text { Agentes }\end{array}$ & $\begin{array}{l}\text { Licenças, patentes e "Know-how"; Conferências, seminários, cursos e } \\
\text { publicações especializadas, feiras, exibições e lojas; Encontros de lazer; } \\
\text { Associações empresariais locais e; Informações de rede baseadas na internet } \\
\text { ou computador }\end{array}$ \\
\hline Cooperação Vertical & $\begin{array}{l}\text { Fornecedores de insumos (equipamentos, materiais, componentes e } \\
\text { softwares) e; Clientes }\end{array}$ \\
\hline Cooperação Horizontal & Concorrentes e outras empresas do setor \\
\hline $\begin{array}{l}\text { Cooperação com instituições de } \\
\text { C\&T }\end{array}$ & Universidade e; Institutos de Pesquisa \\
\hline $\begin{array}{l}\text { Cooperação com Serviços } \\
\text { Especializados }\end{array}$ & $\begin{array}{l}\text { Centros de capacitação profissional, de assistência técnica e de manutenção; } \\
\text { Instituições de testes, ensaios e certificações; Empresas de consultoria }\end{array}$ \\
\hline Cooperação com Demais Agentes & $\begin{array}{l}\text { Representação; Entidades Sindicais; Órgãos de apoio e promoção e Agentes } \\
\text { financeiros }\end{array}$ \\
\hline \multicolumn{2}{|r|}{ 3) Indicadores de Desempenho Inovativo } \\
\hline Inovação em Produtos & $\begin{array}{l}\begin{array}{l}\text { Produto novo para empresa; e } \\
\text { nacional/internacional }\end{array} \\
\end{array}$ \\
\hline Inovação em Processos & Processo novo para a empresa/Processo novo para o setor de atuação \\
\hline
\end{tabular}

O quadro um apresenta os indicadores utilizados para analisar o processo de aprendizado e cooperação, os quais contemplam os principais aspectos relacionados a construção de capacitações locais: 1) esforço inovativo, 2) aprendizagem externa e ações cooperativas e; 3) desempenho inovativo. Para cada indicador algumas variáveis foram estabelecidas para que a análise possa ser efetivada.

Assim, alguns indicadores existem no sentido de analisar e inferir as características de processos de inovação de setores produtivos. Através da consideração e estudo da eficiência cooperativa entre as empresas e dos fatores que podem levar ao aumento da produtividade, pode-se inferir acerca dos procedimentos que interferem nos processos inovativos das empresas. Com isso, pode ser possível realizar um estudo comparativo entre os processos de aprendizagem e cooperação entre duas indústrias de cachaça do brejo paraibano.

\subsection{Contextualização do setor em estudo}

A cachaça e a rapadura são consideradas os principais produtos derivados da cana-deaçúcar, além do açúcar propriamente dito. A cachaça, em particular, pode ser definida como o produto alcoólico obtido pela destilação do mosto fermentado de cana-de-açúcar. Segundo Gonçalves et al. (2008) é a terceira bebida alcoólica mais consumida no mundo; mas esse consumo se dá quase que totalmente no mercado interno brasileiro, visto que o volume exportado é muito baixo.

No país, a cachaça ocupa o segundo lugar no consumo de bebidas alcoólicas, atrás somente da cerveja (MARTINELLI; SPERS; COSTA, 2000). A produção nacional da bebida é estimada em 1,5 bilhões de litros, sendo que menos de $1 \%$ desse volume é exportado. O setor gera uma receita de 
US\$ 500 milhões em média e emprega cerca de 400 mil pessoas, direta e indiretamente no Brasil (BRASIL, MINISTÉRIO DA AGRICULTURA... 2009).

Em relação ao mercado potencial, verifica-se uma possibilidade de ascensão maior do consumo do produto, uma vez que o mesmo está perdendo a conotação pejorativa e alcançando público consumidor cada vez mais exigente. A produção encontra-se principalmente no nordeste, situada nos estados de Pernambuco, Paraíba e Ceará, sendo este um dos subsistemas de produção da cana-de-açúcar no país, o outro é no sudeste. Este último, caracterizado como mais dinâmico e competitivo que o primeiro.

A capacidade instalada nas diversas regiões, o baixo custo de produção, o preço de venda acessível ao consumidor e a ampla rede de distribuição são fatores favoráveis à expansão do setor produtivo de cachaça industrial no Brasil. Dentre os principais fatores que contribuíram para esse processo de desenvolvimento do setor, destacam-se os esforços para o reconhecimento da denominação de origem - cachaça - como produto produzido exclusivamente no Brasil e para a construção de normas e selos de qualidade nas várias esferas (nacional, estadual e regional) (VERDI, 2005).

A cachaça tem adquirido grande demanda no mercado interno e possibilidade de ascensão no mercado externo. Por esse fator, o movimento de organização do setor tem se intensificado, e tem-se observado um crescimento do interesse público e privado em expandir a produção e a comercialização desse produto.

Com relação aos demais derivados da cana-de-açúcar produzidos por pequenos produtores (açúcar mascavo, rapadura e mel), observa-se que o setor é ainda menos dinâmico que o da cachaça. O setor produtivo de rapadura possui elevado nível de informalidade e conservadorismo no sentido de que o sistema de produção não evoluiu ao longo das décadas. É uma atividade carente em recursos financeiros e orientação técnica e o nível de qualificação pessoal é baixo (GONÇALVES et al., 2008).

O processo industrial da cachaça é antigo e conhecido, os engenhos são em sua maioria passados de geração em geração. As melhorias tecnológicas e as mudanças no setor são ainda incipientes. Já na logística de transporte, embalagem e canais de distribuição, a tecnologia pode contribuir em maior quantidade para redução de custos. Empresas de pequeno porte, por exemplo, têm conseguido diversificar com produtos menos intensivos em tecnologia.

Destaca-se assim, a necessidade de maiores incentivos ao desenvolvimento do processo produtivo da cachaça, entretanto, em relação à agroindústria como um todo, e pelo fato de o Brasil ser o único do mundo que domina todos os estágios da produção, sua qualidade é considerada superior e o país gera cadeia produtiva de enorme potencial de expansão.

A experiência da indústria sucroalcooleira não vem de agora e, por mais altos e baixos que o 
setor tenha atravessado ao longo dos séculos, está presente como parte intrínseca da economia do país. Desta forma é de importância significativa o estudo sobre a maneira como se dá a aprendizagem neste setor, como forma principalmente de propiciar inovações.

A seção seguinte aborda os procedimento metodológicos que deram suporte à realização da pesquisa.

\section{Método}

A pesquisa caracteriza-se como de natureza exploratória e descritiva, uma vez que envolveu a exposição e análise das características de inovação e estrutura de aprendizagem de duas empresas agroindustriais. O levantamento de dados ocorreu sob a forma de roteiros de entrevista semiestruturados, sendo a construção deste roteiro baseada nos indicadores propostos por Stallivieri e Souza (2008). Este modelo foi selecionado para aplicação na presente pesquisa porque foi o único encontrado na literatura que aborda indicadores relativos a duas grandes variáveis, como o processo de inovação e o processo de aprendizagem e cooperação. Apesar de estarem intimamente ligados, esses indicadores ainda não haviam sido postos em um único modelo. Fato este que justifica a não utilização de outros modelos como o tripla hélice de Etzkowitz (1995) e Leydesdorff (2000) ou o interativo de Kline e Rorenberg (1986), os quais não evidenciam em maior grandiosidade a aprendizagem e a cooperação, foco de estudo desta pesquisa.

Com a construção do instrumento de pesquisa, verificou-se que análise de conteúdo temática serviu como melhor suporte à interpretação das falas dos entrevistados. Procurou-se identificar as falas que fossem representativas de cada indicador proposto por Stallivieri e Souza (2008) para ser possível promover o diagnóstico das empresas e consequente estudo comparativo. A análise de conteúdo é um tipo de análise do discurso, a qual segundo Bardin (1997) é utilizada para estudar e analisar material qualitativo, buscando-se, desta forma, uma melhor compreensão de uma comunicação ou discurso, de modo a aprofundar suas características gramaticais aliando às características teóricas, além de extrair os aspectos mais relevantes.

Visitas técnicas às empresas foram necessárias para o levantamento de dados não especificados em entrevistas e, assim, a observação não participante foi um recurso também empregado na consolidação dos resultados. Houve acesso a dados secundários das empresas no que concerne a processos de inovação empregado nas mesmas; entretanto, estes dados não foram responsáveis por grande volume de informações contidas no presente estudo.

Por garantir a confidencialidade das empresas e dos dados coletados, foram adotados os codinomes empresa A e empresa B. Na empresa A foram entrevistadas três pessoas incluindo o gerente e dois funcionários relacionados ao processo de fabricação do produto. Na empresa B foram entrevistadas cinco pessoas incluindo também o gerente, o responsável pela produção e três outros 
funcionários.

A empresa A trata-se de um empreendimento de pequeno porte, onde 30 funcionários trabalham para a produção de diversos tipos de rapadura, cachaça, açúcar mascavo e mel. Possui um mercado local, mas existe a intenção de vendar para a região e áreas menos próximas. Tem uma produção semanal de $8.000 \mathrm{~kg}$ de rapadura e de 30.000 litros de cachaça por ano, e está situada no brejo Paraibano.

No que concerne às características da empresa $\mathrm{B}$, pode-se verificar como único produto fabricado a cachaça engarrafada sob algumas diferentes tipologias. É considerada uma empresa de médio porte com um total de 45 funcionários e uma fabricação de 180.000 litros do produto por ano. Trabalha principalmente com o mercado local e regional, entretanto vende em quantidades diferenciadas para todo o país. É considerada uma empresa confiável e com produtos de qualidade em seu ramo de atuação, na região, segundo informações da imprensa local. Está situada também no brejo paraibano.

\section{Análise e discussão dos resultados}

Esta seção aborda os resultados obtidos com as entrevistas realizadas nas empresas, além de apresentar uma breve contextualização do setor estudado.

\subsection{Comparativo dos processos de aprendizagem e cooperação nas indústrias de cachaça do Brejo Paraibano}

Conforme especificado, foram analisadas duas empresas do setor agroindustrial. O quadro dois a seguir expõe o diagnóstico realizado na pesquisa para as as empresas A e B a partir dos indicadores de esforço inovativo.

\begin{tabular}{|l|l|l|}
\multicolumn{1}{|c|}{ Quadro 2 - Análise dos indicadores de esforço inovativo } \\
\hline \multicolumn{1}{|c|}{ Indicadores de Esforço Inovativo } \\
\hline \multicolumn{1}{|c|}{ Empresa A } \\
\hline $\begin{array}{l}\text { Indores } \\
\text { Realização de P\&D }\end{array}$ & $\begin{array}{l}\text { Aquisição externa de P\&D incipiente. } \\
\text { E a realização interna de P\&D é feita } \\
\text { sob demanda. }\end{array}$ & $\begin{array}{l}\text { Aquisição freqüente de P\&D. Realização } \\
\text { interna de P\&D constante. }\end{array}$ \\
\hline $\begin{array}{l}\text { Constância na } \\
\text { Aquisição de Novas } \\
\text { Tecnologias }\end{array}$ & $\begin{array}{l}\text { Baixa aquisição de máquinas, } \\
\text { equipamentos e outros melhoramentos } \\
\text { tecnológicos. }\end{array}$ & $\begin{array}{l}\text { Aquisição de máquinas e equipamentos, bem } \\
\text { como outras tecnologias de forma moderada. }\end{array}$ \\
\hline $\begin{array}{l}\text { Constância no esforço } \\
\text { Pré-Inovativo }\end{array}$ & $\begin{array}{l}\text { Baixa atividade em projetos de elevado } \\
\text { teor tecnológico e treinamento. }\end{array}$ & $\begin{array}{l}\text { Esforço inovativo moderado com introdução de } \\
\text { novas tecnologias e melhoramentos. }\end{array}$ \\
\hline $\begin{array}{l}\text { Constância na } \\
\begin{array}{l}\text { Atualização } \\
\text { Organizacional }\end{array}\end{array}$ & $\begin{array}{l}\text { Ausência de programas de gestão da } \\
\text { qualidade. Formas de comercialização } \\
\text { e distribuição sem inovações. }\end{array}$ & $\begin{array}{l}\text { Presença de programa de gestão de qualidade } \\
\text { dos produtos. Comercialização e distribuição } \\
\text { padrão. }\end{array}$ \\
\hline $\begin{array}{l}\text { Esforço de } \\
\text { Treinamento }\end{array}$ & $\begin{array}{l}\text { Todo treinamento é realizado } \\
\text { internamente. }\end{array}$ & \begin{tabular}{l} 
Todo treinamento é realizado internamente. \\
\hline
\end{tabular} \\
\hline
\end{tabular}




\begin{tabular}{|l|l|l|}
\hline $\begin{array}{l}\text { Esforço de Absorção } \\
\text { de Recursos Humanos }\end{array}$ & $\begin{array}{l}\text { Não há absorção de mão-de-obra } \\
\text { especializada para a atividade. Toda ela } \\
\text { é formada dentro da empresa. }\end{array}$ & $\begin{array}{l}\text { A necessidade de mão-de-obra especializada é } \\
\text { suprida através de parcerias com laboratórios. E } \\
\text { há um contingente considerável de mão-de-obra } \\
\text { menos especializada disponível para o trabalho } \\
\text { nas proximidades da empresa. }\end{array}$ \\
\hline $\begin{array}{l}\text { Aprendizagem } \\
\text { Interna: } \\
\text { Departamento de } \\
\text { P\&D }\end{array}$ & Ausência de departamento de P\&D. & Ausência de departamento de P\&D. \\
\hline $\begin{array}{l}\text { Aprendizagem } \\
\text { Interna: Demais }\end{array}$ & $\begin{array}{l}\text { As demais fontes se concentram no } \\
\text { firetor da empresa e no responsável } \\
\text { pela produção da cana-de-açúcar. }\end{array}$ & $\begin{array}{l}\text { As demais fontes de aprendizagem partem de } \\
\text { iniciativas dos setores administrativo e de } \\
\text { produção. O gerente é considerado um decisivo } \\
\text { e importante fator de aprendizagem e } \\
\text { desenvolvimento. }\end{array}$ \\
\hline \hline
\end{tabular}

Fonte: Elaboração própria (2011)

Conforme análise apresentada no quadro dois, observa-se que a empresa B está numa situação mais favorável em relação ao fator $\mathrm{P} \& \mathrm{D}$ que a empresa $\mathrm{A}$. Isto porque ela adquire este fator por intermédio de outras instituições. Uma de suas principais colaboradoras é uma instituição de ensino superior situada no estado de São Paulo. A interação é considerada freqüente, uma vez que pesquisadores analisam quimicamente as características do produto no intuito de seu desenvolvimento e manutenção da qualidade. E existem trocas de informações mensais sobre novos produtos e processos. Enquanto que na empresa A essa aquisição de P\&D é incipiente, realizada apenas sob demanda e através de interações informais com uma universidade. A seguinte opinião do gerente explana a situação da empresa A no que concerne a este aspecto:

"Nossa frequência de pesquisa e desenvolvimento não é grande. Na verdade, agente precisa de mais investimento nessa área. $\mathrm{O}$ setor da cachaça está crescendo muito e isso justifica mais P\&D [...] Conheço algumas pessoas de universidades que se propõe a verificar nossa cachaça, mas é tudo informal".

Uma das principais diferenças entre essas duas empresas no que concerne à este fator é que enquanto que a empresa $B$ existe a manutenção de contatos frequentes com instituições de pesquisa, o gestor da empresa A não tem a prática de estabelecer comunicações contínuas e busca de informações sobre melhorias para seu produto.

A constância no esforço pré-inovativo na empresa B é moderada. Nos últimos cinco anos, aumentou-se a tipologia de produtos com a introdução de cachaça com sabores distintos, houve também a utilização de novos materiais (matéria-prima e componentes) e inovações na apresentação do produto, com garrafas de diferentes tamanhos e características. Na empresa A ainda é baixo o número de aquisições de máquinas e equipamentos para produção da cachaça. Nos últimos anos o investimento se deu apenas em armazenagem da cachaça e engarrafamento, no sentido de atender as normas da vigilância sanitária. Do ponto de vista de melhorias no processo produtivo, apesar de o setor não proporcionar grandes avanços neste campo, houve melhorias apenas no maquinário existente. $\mathrm{O}$ gestor da empresa $\mathrm{B}$ tem a seguinte opinião sobre a qualidade dos produtos e sua 
inovação:

\begin{abstract}
"Introduzimos algumas novas tipologias de produto, que fundamentamos numa pesquisa com nossos principais consumidores e clientes. Acredito que nossos produtos são de qualidade porque são sempre reconhecidos. No fim do ano passado fomos eleitos por uma revista de circulação nacional como a segunda melhor cachaça do país. [...] Quando agente fala de qualidade na nossa empresa, agente tem principalmente o reconhecimento".
\end{abstract}

Quanto à atualização organizacional, ambas as empresas não desenvolveram programas para tal modernização. Porém, na empresa B há um controle rigoroso sobre a qualidade dos produtos. Conforme observou-se, e pela própria explanação do diretor da empresa, a mesma foi elencada no ranking nacional das empresas que possuem elevado padrão de qualidade em dois momentos distintos. Já na empresa A o controle de qualidade não é realizado de forma rigorosa e freqüente, a qualidade da cachaça é mais advinda do próprio conhecimento dos funcionários, de uma maneira empírica, sobre as características do produto e sistema de produção.

Em relação ao treinamento dos recursos humanos, na empresa $\mathrm{B}$ devido o processo produtivo requerer um preparo e treinamento relativamente pequenos, a constância é média. Nos últimos cinco anos, os funcionários participaram de processos de treinamento realizados dentro da própria indústria. Com uma instrução relativamente pequena, os mesmos ficam conhecedores de todo o processo produtivo. De forma semelhante esse processo ocorre na empresa A. O treinamento dos funcionários é realizado internamente através da prática e vivência com a atividade. $\mathrm{Na}$ verdade, as próprias características do setor sucroalcooleiro e especificamente da fabricação da cachaça não impõe a necessidade de um preparo extenso e contínuo. As opiniões de um dos funcionários da empresa B e da empresa A, nessa ordem, reforçam esta constatação:

\footnotetext{
"Quando agente é admitido na empresa, passamos por um treinamento que nos deixa preparados para o desempenho da atividade de produção da cachaça. Tudo que for além disso também podemos ser preparados. Acho que também o processo não é tão complicado ou difícil de aprender".

"A constância de treinamento não é alta. Agente aprende tudo logo que começamos a trabalhar no engenho e vamos tendo maior experiência com o tempo. [...] é, esse tipo de produção aqui não pede muito treinamento".
}

Conforme verificado, ambas as empresas não possuem um departamento especializado em $\mathrm{P} \& \mathrm{D}$, sendo as principais colaborações nesse sentido vindas de agentes externos. No entanto, na empresa A existe um estímulo direcionado aos funcionários no sentido de participar e cooperar para o fomento de melhores produtos e processos. Os fundionários entrevistados mostraram esta opinião, sendo a fala de um deles, a seguir, um exemplo disto.

"Nós ficamos à vontade para sugerir e conversar sobre novidades e problemas que possam envolver o produto ou até mesmo o setor [...]. Também podemos realizar nosso trabalho como agente achar melhor". 
No que se refere ao indicador aprendizagem interna, identificou-se que na empresa $\mathrm{B}$ o diretor é o principal responsável pela iniciativa de introduzir idéias relacionadas à inovação e desenvolvimento dos produtos. Dada as características do engenho, por ser uma empresa de médio porte e sistema de produção com layout simplificado, é possível ao gerente se posicionar no sentido de desenvolver melhores técnicas de produção e produto, além das tarefas às quais se submete. Para a empresa A as intenções de inovação estão concentradas no diretor da empresa e na pessoa responsável pela colheita da cana-de-açúcar. No entanto, verificou-se a possibilidade ou abertura por parte da empresa aos seus funcionários no sentido de estes apresentarem seus pontos de vista. Pontua-se que, nas empresas pesquisadas, um fator que as diferencia neste aspecto são as características do modo de administrar de cada um dos gestores dos engenhos. Eles mesmos podem ser os responsáveis pela produção de inovação e conhecimento na empresa ou podem propiciar aos seus funcionários os meios necessários à esta iniciativa.

No que concerne aos indicadores de aprendizagem externa e ações cooperativas, o diagnóstico para cada um pode ser verificado pela análise do quadro três a seguir:

Quadro 3 - Análise dos indicadores de aprendizagem externa e ações cooperativas

\begin{tabular}{|c|c|c|}
\hline \multicolumn{3}{|c|}{ Indicadores de Aprendizagem Externa e Ações Cooperativas } \\
\hline Indicadores & Empresa A & Empresa B \\
\hline $\begin{array}{l}\text { Aprendizagem } \\
\text { Vertical }\end{array}$ & $\begin{array}{l}\text { Não há interação ou troca de } \\
\text { informação com fornecedores de } \\
\text { insumos }\end{array}$ & Baixa interação com fornecedores. \\
\hline $\begin{array}{l}\text { Aprendizagem } \\
\text { Horizontal }\end{array}$ & $\begin{array}{l}\begin{array}{l}\text { Ausência de interação com } \\
\text { concorrentes. }\end{array} \\
\end{array}$ & Ausência de interação com concorrentes. \\
\hline $\begin{array}{l}\text { Aprendizagem com } \\
\text { Instituições de } \\
\text { Ciência e Tecnologia }\end{array}$ & $\begin{array}{l}\text { Interações eventuais com a } \\
\text { universidade. }\end{array}$ & $\begin{array}{l}\text { Interação freqüente com laboratórios de } \\
\text { universidades. }\end{array}$ \\
\hline $\begin{array}{l}\text { Aprendizagem com } \\
\text { Serviços } \\
\text { Especializados }\end{array}$ & Ausência de interações. & Baixa interação, realizada apenas sob demanda. \\
\hline $\begin{array}{l}\text { Aprendizagem com } \\
\text { Demais Agentes }\end{array}$ & $\begin{array}{l}\begin{array}{l}\text { Presença moderada em feiras e } \\
\text { eventos do setor. }\end{array} \\
\end{array}$ & Freqüente presença em feiras e eventos do setor. \\
\hline Cooperação Vertical & Ausência de cooperação. & Baixa cooperação com fornecedores. \\
\hline $\begin{array}{l}\text { Cooperação } \\
\text { Horizontal }\end{array}$ & $\begin{array}{l}\text { Ausência de cooperação com } \\
\text { concorrentes }\end{array}$ & $\begin{array}{l}\text { Não existe uma cultura para formalização de elos } \\
\text { de cooperação. Há uma ocorrência fraca de } \\
\text { encontros informais para discussão de problemas } \\
\text { para o setor e para compartilhamento de } \\
\text { experiências (inovação). }\end{array}$ \\
\hline $\begin{array}{l}\text { Cooperação com } \\
\text { instituições de C\&T }\end{array}$ & $\begin{array}{l}\text { Eventuais interações para cooperação } \\
\text { com universidades. }\end{array}$ & Cooperação freqüente com universidades. \\
\hline $\begin{array}{l}\text { Cooperação com } \\
\text { Serviços } \\
\text { Especializados }\end{array}$ & Ausência de cooperação. & Ausência de cooperação \\
\hline $\begin{array}{l}\text { Cooperação com } \\
\text { Demais Agentes }\end{array}$ & Ausência de cooperação. & Cooperação moderada com órgãos públicos. \\
\hline
\end{tabular}

Fonte: Elaboração própria (2011) 
Os indicadores expostos no quadro três apresentam como acontecem as relações de aprendizagem entre as empresas, bem como as relações de cooperação. Em relação à aprendizagem vertical, foi identificado nas empresas A e B baixa ou nenhuma interação no sentido da aprendizagem com fornecedores, uma vez que estes se encontram em sua grande maioria distantes das empresas, e a relação se dá basicamente por compra e venda. Relações com concorrentes não são freqüentes, uma vez que a própria estrutura de organização do setor e as empresas da localidade não mantém uma prática frequente de troca de informações e idéias. E não existem organizações setoriais. O gerente e o responsável pela produção da empresa B acreditam ser um problema a questão da aprendizagem vertical e horizontal.

\begin{abstract}
"Acho que um grande problema aqui do nosso setor é a falta de comunicação entre todo mundo. Não existe uma prática frequente de troca de idéias entre os fornecedores ou parceiros, ou entre os concorrentes. E isso podia ser um fator a nosso favor, se agente se reunisse mais, e soubesse dos problemas que os outros enfrentam tanto na produção da cana quanto na fabricação mesmo".

"Não existe muita aprendizagem entre as empresas. Cada um procura fazer a produção por experiência própria. Acho que com os fornecedores agente tem mais abertura pra falar. Inclusive eles nos ajudaram na mudança de nossas garrafas e dos rótulos, deram idéias. Mas já os concorrentes não conversam muito. É uma questão de hábito mesmo sabe [...]”
\end{abstract}

Os pesquisados da empresa A também concordam que não há muita aprendizagem, cooperação ou troca de idéias entre os agentes envolvidos, no entanto não acreditam ser este um grande problema para o setor e para a própria empresa.

\begin{abstract}
"A aprendizagem entre as empresas não é muito frequente. Mas nós temos grande conhecimento pra realizar nossas atividades, temos criatividade. E acho que o tipo de setor que agente trabalha não pede muita aprendizagem entre os agentes. A agroindústria requer muita experiência, e você sabe que nem sempre isso vem com conversas ou troca de informações".
\end{abstract}

A aprendizagem com serviços especializados na empresa B se mantém sob constância pequena. Existem necessidades do ponto de vista tecnológico, e parcerias nesse sentido seriam de importância significativa. Foi identificado que o gerente mantém interações com alguns serviços de consultoria dada a necessidade que há, segundo ele, da implantação de um processo de comunicação interna que funcionasse como kanbans de produção. A afirmação de um funcionário do setor de produção da empresa B reforça esta constatação.

"O gerente teve a idéia de inserir alguma coisa que pudesse informar a cada parte da produção o momento em que cada uma terminasse sua tarefa, assim fica mais rápido todo o processo. Acho que só falta saber como se pode fazer isso".

Já na empresa A, esse tipo de cooperação é ausente.

No que se refere à aprendizagem com os demais agentes, foi identificado na empresa B uma média constância na cooperação com outros agentes produtivos. Alguns engenhos, sindicatos e 
pessoas específicas contribuem no sentido de aprimorar as práticas gerenciais e produtivas da empresa, além da participação em feiras e eventos específicos para o setor. Na empresa A verificase o desenvolvimento dos processos de aprendizagem com os demais agentes apenas através de feiras e exibições do próprio setor.

Não existe uma cooperação significativa com serviços especializados. Porém nos últimos cinco anos, precisamente em 2006, a empresa B contou com a cooperação de um fornecedor de equipamentos para o design de seus produtos. E órgãos públicos têm contribuído no sentido de viabilizar melhor infra-estrutura de acesso à empresa. Porém, não é vista como uma cooperação de frequiência alta. $\mathrm{O}$ gerente da empresa $\mathrm{B}$ tem a seguinte opinião sobre a cooperação com serviços especializados.

\begin{abstract}
“A estrada que dá acesso aqui à nossa fábrica é de barro. Então sempre estamos precisando que ele seja cuidado, principalmente nos períodos de chuva em que fica difícil o acesso. A prefeitura não ajuda com muita frequência, e acredito que não é interesse de outros órgãos ajudar nesse sentido".
\end{abstract}

A contratação de serviços especializados por parte da empresa A se dá apenas sob demanda, quando há, por exemplo, mudança nos rótulos e nas embalagens dos produtos. Destaca-se que a falta deste tipo de cooperação pode inviabilizar processos de inovação às empresas, uma vez que contribuem com experiências, idéias e opiniões diferentes.

$\mathrm{Na}$ verdade, verifica-se nas empresas A e B a não aplicabilidade de muitos fatores que contribuem à inovação. Observa-se e justifica-se este fato pela não ocorrência de um ambiente propício à cooperação e interação mútua entre empresas. No entanto, apesar desta característica, a cachaça é um produto que possui grande representatividade na região, destacando-se a grande quantidade de engenhos e a proximidade das empresas pesquisadas de um APL - Arranjo Produtivo Local - do produto. Mesmo com essa quantidade de engenhos e consequente localização favorável, não existe uma cultura que contribua ao fomento de iniciativas empreendedoras e de integração, no sentido de aperfeiçoar e desenvolver a capacidade inovativa dessas empresas.

Para os indicadores relacionados ao desempenho inovativo das empresas, o diagnóstico está explicitado no quadro quatro a seguir:

Quadro 4 - Análise dos indicadores de desempenho inovativo

\begin{tabular}{||l|l||l|}
\hline \multicolumn{2}{|c|}{ Indicadores de Desempenho Inovativo } \\
\hline \hline \multicolumn{1}{|c|}{ Indicadores } & \multicolumn{1}{|c|}{ Empresa A } & \multicolumn{1}{|c|}{ Empresa B } \\
\hline $\begin{array}{l}\text { Inovação em } \\
\text { Produtos }\end{array}$ & $\begin{array}{l}\text { Existência de intenções de inovação no } \\
\text { produto. }\end{array}$ & Forte presença de inovação em produtos. \\
\hline $\begin{array}{l}\text { Inovação em } \\
\text { Processos }\end{array}$ & $\begin{array}{l}\text { Existência de adaptações no processo } \\
\text { produtivo, considerado novo para a } \\
\text { empresa, mas não para o setor. }\end{array}$ & $\begin{array}{l}\text { Adaptações internas que consistem em inovação } \\
\text { para a empresa, mas melhoramento tecnológico } \\
\text { para o setor. }\end{array}$ \\
\hline
\end{tabular}

Fonte: Elaboração própria (2011) 
Os indicadores de desempenho inovativo abordam a inovação em produtos e a inovação em processos. E ambos apresentam algumas diferenças entre as empresas pesquisadas. Na empresa A, houve iniciativas e até alguns testes realizados pelo produtor para o desenvolvimento de novas variações no sabor da cachaça. Tratam-se de intenções por parte do administrador de inserir estas tipologias de produto, mas que não ocorreram ainda de fato. A falta de interação da empresa com outros agentes que forneçam conhecimentos especializados na área cria um problema no quesito inovação em produtos. As inovações nos processos foram realizadas internamente pelos próprios funcionários, no maquinário já existente, na intenção de obter maior produtividade dos equipamentos. O gerente da empresa A acredita que maiores investimentos poderiam proporcionar a inovação nos produtos almejada.

\footnotetext{
"Para que possamos sair da intenção e fazer mesmo a cachaça precisamos de mais investimento e maior capital. Pois tem a compra de frutas, tem a divulgação que precisamos fazer, tem os testes pra saber se a cachaça vai realmente dar certo. E à princípio são muitas prioridades que temos, por isso ainda não implantamos a inovação".
}

Já na empresa B houve inovação nos últimos anos. Esta passou a fornecer produtos com design e tipologias diferenciadas: uma cachaça com sabores de frutas e adição de incrementos como vegetais. As garrafas e rótulos também sofreram modificação dada a introdução destas novas tipologias. E para isto o gerente afirma que necessitou de uma interação mais frequente com o fornecedor responsável pela sua fabricação. Com relação às inovações de processo, houve aquisição de novos equipamentos, mais modernos e com maior eficiência, bem como adaptações internas para maior produtividade. A opinião de um funcionário da empresa mostra esta constatação. "Modificamos a moenda, que antes era antiga e produzia menos por uma moenda capaz de
produzir mais $[\ldots]$ ".

Apesar de não haver uma cultura de interação mútua, coloca-se que a empresa B possui um mercado estável e maior capacidade de mudar seus produtos e processos, em detrimento da empresa A. Dentre essas modificações, destaca-se a substituição de sua moenda antiga por uma moenda modernizada, composta por mancais de madeira-metal e novos cilindros; o que melhorou a captação de sacarose para $85 \%$ e o seu consequente rendimento. Outro ponto a destacar, este em relação à atualização organizacional e que proporcionou inclusive melhorias do ponto de vista de marketing foi a construção de um restaurante e de uma loja no próprio engenho e empresa, o que contribuiu para as vendas do produto e de alguns itens em particular como camisas, broches, entre outros. Destaca-se também o ocorrência frequente de uma trilha ecológica, que melhorou as relações entre funcionários e comunidade.

A empresa A, apesar de estrutura consolidada no que concerne ao seu sistema produtivo, necessita de procedimentos que garantam maior interação - cooperação e aprendizagem - entre as 
empresas da região. $\mathrm{Na}$ empresa $\mathrm{B}$, apesar de não haver também interação, observou-se maior capacidade de inovação.

\section{Considerações finais}

A capacidade de adquirir e criar conhecimento a partir de interações e elos de cooperação constitui-se numa importante ferramenta que eleva a competitividade das empresas. Entretanto, utilizar informações como um fator competitivo só será possível se as empresas estiverem direcionadas ou propensas a absorver e criar novos conhecimentos.

É possível destacar preliminarmente que o objetivo foi alcançado visto que destacou-se características referentes à inovação e aprendizado nas duas empresas pesquisadas, fatores que ficaram claros com as entrevistas realizadas. Estas entrevistas propiciaram diagnosticar, por exemplo, que a inovação em processos foi importante mas não se referiu a uma inovação para o setor, e sim para a empresa estudada. Constatou-se que as entrevistas foram satisfatórias e significativas, uma vez que foi possível pesquisar os gerentes e os funcionários diretamente envolvidos com o processo de produção das empresas.

Constata-se que o método utilizado foi conclusivo, ou seja, o modelo de Stallivieri e Souza (2008) propiciou analisar concretamente as empresas pesquisadas. A maioria dos indicadores apresentados no modelo puderam ser analisados, considerando as especificidades e características singulares das indústrias A e B. Outros estudos, no entanto, precisam ser realizados ainda com este modelo para um melhor entendimento e aprimoramento de sua aplicação.

Considerando estas verificações e a partir da pesquisa realizada nas empresas em questão, foi constatado na empresa A uma ausência de interesse em interagir e cooperar com outros agentes no sentido de aprimorar as habilidades e competências para inovar. Dessa forma, para a empresa o principal limitador de seu crescimento no que diz respeito ao aprendizado para inovação é a falta de uma cultura para interagir e adquirir conhecimento. No entanto, essa falta de cultura não é derivada de características próprias da empresa e sua administração, mas de toda a cadeia de produção da cachaça da localidade, de todos os empresários e envolvidos com o setor, que não estão propensos a adquirir uma postura de interação mútua entre os agentes em questão. A empresa A necessita aperfeiçoar-se tanto em relação à inovação nos produtos e processos como na constância de realização de $\mathrm{P} \& \mathrm{D}$ e de atualização organizacional, características essas que favorecem explicitamente a inovação às empresas.

Em relação à empresa $\mathrm{B}$, verificou-se a necessidade de inovação relacionada à tecnologia de informação. A empresa julga necessária a implantação de um ERP (Enterprise Resource Planning) para aperfeiçoar o acompanhamento de todas as etapas do processo produtivo. Atualmente, este acompanhamento é feito manualmente, o que implica em maior tempo e trabalho de execução. 
Observou-se, a partir do diagnóstico desta necessidade feito pelo próprio gerente, que uma característica da empresa e do estilo gerencial deste seu administrador é a busca por inovação constante; tanto em produtos como igualmente em processos.

Apesar de a empresa B não fazer parte de um segmento organizado, com trocas de informações e idéias, a mesma pode ser vista como tendo um mercado consolidado e firme, dado o fato de a mesma produzir a cana utilizada, obter lucro pelo bagaço da produção vendido a outras empresas e pelas iniciativas freqüentes de inovação nos produtos. O que pode ser visto pela introdução de licores e diferentes frutas no processo de fabricação da cachaça.

Essa principal diferença entre as duas empresas pode ser originada entre outros fatores por características dos próprios gerentes no que concerne ao seu estilo de administrar.

Apesar das dificuldades encontradas nas empresas A e B relacionadas à interação e cooperação, existe outro fator que é fundamental na contribuição dos processos de aprendizagem, que é a ambiência. A cultura social de cooperação aprimorada pelos atributos de uma localidade favorece o comportamento cooperativo entre indivíduos. Dessa forma, apesar da região do Brejo Paraibano ter um Arranjo Produtivo Local de cachaça do Estado, um fator primordial, que é a cooperação, é inexistente e interfere no comportamento das empresas.

É importante observar também que as empresas pesquisadas, apesar de sua proximidade e participação no mesmo APL da cachaça possuem características distintas, o que foi possível verificar a partir do objetivo proposto.

Há que se considerar, para as empresas pesquisadas, os meios que podem ser fomentados para a criação de um ambiente favorável à troca de informações dada as características e necessidades do setor. Como também, à empresa A é necessário maior atualização e inovação, sendo esta sua principal diferença da empresa $\mathrm{B}$, a qual está bem à frente no que concerne à estes indicadores.

Como fatores que podem ser considerados benéficos às duas empresas destaca-se a proximidade com mercados consumidores e pequenas atuações de parceiros em destaque o setor público. Apesar das pessoas da comunidade que circunda as empresas não terem consciência do que representa a cadeia produtiva, e apesar também da não efetividade de processos de cooperação, as empresas podem ser vistas como competitivas, com produtividade e imagem consolidada no mercado.

\subsection{Sugestões para pesquisas futuras}

É possível evidenciar a possibilidade de pesquisas futuras, a partir de melhorias, por exemplo, realizadas na presente pesquisa. Constata-se que o tema pode continuar a ser discutido no âmbito de todo o APL o qual as se encontra as indústrias estudadas. Um número maior de empresas 
pode ser pesquisado, inclusive para confrontar dados apresentados nesta pesquisa. Como também outros APL’s ou empresas em particular podem ser estudadas a partir do modelo de Stallivieri e Souza (2008). Este último pode não ser tão conclusivo ou apresentar dados significativos no âmbito de outras pesquisas, com outros setores ou ramos de negócio.

\begin{abstract}
The ability to build new skills through learning and cooperation mechanisms becomes essential to obtain competitive advantages. Companies that build an environment for exchange of knowledge, information and experiences are more likely to develop mechanisms for differentiation in products and processes, obtaining with that larger innovation. Thus, this study aims to conduct a comparative study of learning and cooperation processes in two industries of rum in Brejo Paraibano from the perspective of indicators proposed by Stallivieri and Souza (2008). The research is characterized as exploratory and descriptive, since it involved the exposure and analysis of the characteristics of innovation and learning structure of two agribusiness companies. The results point that companies present external difficulties related to the lack of a social culture of cooperation and learning in the place, what doesn't favor the innovation of the companies. However, it is possible to observe that one of the companies introduced some innovations, counting mainly with the administrator's intrinsic characteristics in your project of looking for new product typologies.
\end{abstract}

Key-words: learning; innovation; industry of rum.

\title{
Referências
}

ALBAGLI, S.; MACIEL, M. L. Informação e conhecimento na inovação e no desenvolvimento local. Ciência da Informação, v. 33, n. 3, 2004.

cross ref

BARDIN, L. Análise de Conteúdo. Lisboa: Edições 70, 1997.

BESSANT, J.; KAPLINSKY, R.; LAMMING, R. Using supply chains to transfer learning about best practices: a report to the Department of Trade and Industry. Mimeo, CENTRIM, Brighton University, Brighton, 1999.

BRASIL, Ministério da Agricultura, Pecuária e Abastecimento. O setor produtivo da cachaça. Disponível em: <http://www.agricultura.gov.br>. Acesso em: jun. 2009.

CAMPOS, R. R. et al.. Aprendizagem por interação: pequenas empresas em sistemas produtivos e inovativos locais. In: LASTRES, H. M. M., CASSIOLATO, J. E.; MACIEL, M. L. (org.) Pequena empresa: cooperação e desenvolvimento local. Cap. 3. Rio de Janeiro: Relume Dumará: UFRJ, Instituto de Economia, p. 51 - 66, 2003.

CASAROTTO FILHO, N.; PIRES, L.M. Redes de pequenas empresas e desenvolvimento local. São Paulo: Atlas, 1999.

CASSIOLATO, J. E., BRITTO, J.; VARGAS, M. A. Arranjos cooperativos e inovação na indústria brasileira. In: DE NEGRI, J. A. e SALERMO, M. S. (org.) Inovações, padrões tecnológicos e desempenho das firmas industriais brasileiras. Cap. 13. Brasília: IPEA, p. 511 - 576, 2005.

CASSIOLATO, J. E.; LASTRES, H. M. M. O enfoque em sistemas produtivos e inovações locais. In: FISCHER, T. (Org). Gestão do desenvolvimento e poderes locais: marcos teóricos e avaliação. Salvador, BA: casa da qualidade, 2002.

DAHLMAN, C.; ROSS-LARSON, B.; WESTPHAL, L. E. Managing technological development: lessons from the newly industrializing countries. In World Development, v. 15, n. 6, p.759- 75, 1987. 
EDVINSSON, L.; MALONE, M. Capital Intelectual: Descobrindo o Valor Real da sua Empresa pela Identificação de seus Valores Internos. São Paulo: Makron Books, 1998.

ETZKOWITZ, H.; LEYDESDORFF, L. The Triple Helix-University- Industry-Government relations: a laboratory for knowledge-based economic development. EASST Review, v. 14, n. 1, p.14-19, 1995.

. The dynamics of innovation: from National Systems and "Mode 2" to a Triple Helix of university-industrygovernment relations. Research Policy, v. 29, Elsevier Science B.V. 2000.

GONÇALVES, M. F.; VIDAL, M F., FIGUEIREDO JÚNIOR, C. A. Cachaça e rapadura na área de jurisdição do BNB: produção, tecnologia e mercado. Fortaleza: Banco do Nordeste do Brasil, 2008.

KLINE, SJ.; ROSENBERG, N. An overview of innovation, In R Landau \& N Rosenberg (eds.). The positive sum strategy. National Academy Press, Washington. p. 275-306, 1986.

LALL, S. Technological capabilities and industrialization. World Development, v. 20, n. 2, p.165- 86, 1992. crossef

LALL, S. Technological Capabilities. In: Salomon, J. J. et al. (orgs.), The Uncertain Quest: Science technology and development. Tóquio: UN University Press, 1994.

LUNDVALL, B.- $\AA$. (ed.). National innovation systems: towards a theory of innovation and interactive learning. Londres: Pinter, 1992.

MALERBA, F. Learning by firms and incremental technical change. Great Britain: The Economic Journal, v. 102, p. 845-859, 1992.

cross ref

MARTINELLI, D. P.; SPERS, E. E.; COSTA, A. F. Ypioca: introduzindo uma bebida genuinamente brasileira no mercado global. In: Congresso Anual do Pensa (PROGRAMA DE ESTUDOS DOS NEGÓCIOS DE SISTEMA INDUSTRIAL), 10, 2000. Anais... São Paulo: USP, 2000.

MCGEE, J. V.; PRUSAK, L Gerenciamento estratégico da informação: aumente a competitividade e a eficiência de sua empresa utilizando a informação como uma ferramenta estratégica. Rio de Janeiro: Campus, 1994.

NELSON, R. R.; WINTER, S. G. Evolutionary theorizing in economics. Journal of Economic Perspectives, v. 16, n. 2 , p. $23-46,2002$.

cross ref

STALLIVIERI, F.; SOUZA, J. G. Processos de aprendizagem e cooperação: uma análise exploratória da influência sobre o desempenho inovativo. In: ENCONTRO NACIONAL DE ECONOMIA, 36, 2008, Salvador. Anais... Salvador: 2008 .

VERDI, A. R. The benefits of efficient governance mechanisms to artisan cachaça territories: strategies for competitiveness and development. In: INTERNATIONAL PENSA CONFERENCE, 2005, Ribeirão Preto. Anais... Ribeirão Preto. 2005, 1 CD.

\section{Dados dos autores:}

Nome completo: Nívea Marcela Marques Nascimento de Macêdo

Filiação institucional: Centro Universitário de João Pessoa - UNIPÊ

Departamento: Administração e Contabilidade

Função ou cargo ocupado: Professora 
Endereço completo para correspondência: Rua João Galiza de Andrade, nº 349, edifício. Ouro Velho, apt. 204, Jardim Cidade Universitária, João Pessoa - PB, cep: 58051-180.

Telefones para contato: (83) 9990-0923

e-mail: niveamarcela@ig.com.br

Nome completo: Raquel Andrade Barros

Filiação institucional: Universidade Federal de Campina Grande

Departamento: Ciências Contábeis

Função ou cargo ocupado: Professora

Endereço completo para correspondência (bairro, cidade, estado, país e CEP): Rua Aprígio Ferreira Leite, 36, Catolé. Campina Grande - PB. CEP: 58410-515

Telefones para contato: (83) 8854-2867 / (83) 3331-1353

e-mail: barrosrab@gmail.com

Nome completo: Gesinaldo Ataíde Cândido

Filiação institucional: Universidade Federal de Campina Grande

Departamento: Administração

Função ou cargo ocupado: Professor Titular em Administração Geral

Endereço completo para correspondência (bairro, cidade, estado, país e CEP): Rua Infante Dom Henrique, 380/301, Tambaú, CEP: 58039-150, João Pessoa - PB

Telefones para contato: 8321011484 / 8388530009

e-mail: gesinaldo@pq.cnpq.br

Enviado em: 13/04/2011

Aprovado em: 21/12/2011 